\title{
Products Liability, Signaling ANd Disclosure
}

by

Andrew F. Daughety and Jennifer F. Reinganum

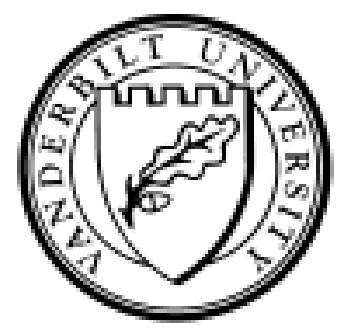

Working Paper No. 06-W25

December 2006

\section{DEPARTMENT OF ECONOMICS \\ VANDERBILT UNIVERSITY \\ NASHVILLE, TN 37235}

www.vanderbilt.edu/econ 


\title{
Products Liability, Signaling and Disclosure
}

\author{
Andrew F. Daughety \\ Jennifer F. Reinganum \\ Department of Economics \\ and Law School \\ Vanderbilt University \\ Nashville, TN 37235 \\ andrew.f.daughety@vanderbilt.edu \\ jennifer.f.reinganum@vanderbilt.edu
}

December 2006 


\title{
Products Liability, Signaling and Disclosure
}

\author{
Andrew F. Daughety \\ Jennifer F. Reinganum
}

\begin{abstract}
In this paper we examine the behavior of a firm that produces a product with a privatelyobserved safety attribute; that is, consumers cannot observe directly the product's safety. The firm may, at a cost, disclose its safety prior to sale; alternatively, if a firm does not disclose its safety then consumers can attempt to infer its safety from the price charged. The liability system is important because it is a determinant of the firm's full marginal cost, which consists of both manufacturing cost and liability cost. If the firm does not bear substantial liability for a consumer's harm, then the firm's marginal cost consists mainly of manufacturing cost, which is presumably higher for safer products. On the other hand, if the firm does bear substantial liability for a consumer's harm, then the firm's marginal cost consists of both manufacturing cost and liability cost. In this case, it is quite possible for a firm producing a safer product to have lower full marginal cost. We characterize the firm's equilibrium disclosure and pricing behavior, and compare that behavior and the associated welfare to what would occur under a regime of mandatory disclosure. We derive a range of disclosure costs that would induce a high-safety firm to choose disclosure over signaling. When the firm's full marginal cost is increasing (decreasing) in safety, a firm with a high-safety product will sometimes inefficiently choose to signal rather than disclose (disclose rather than to signal). Furthermore, we find that whether ex ante information regulation (in the form of mandatory disclosure) or reliance on ex post liability that induces information revelation is the better policy also depends upon whether the firm faces substantial liability for a consumer's harm. Finally, we find that a small fraction of naively optimistic consumers (who always buy as if the product were of high safety) leads to higher profits for both less-safe and safer products, and a reduced incentive for voluntary disclosure.
\end{abstract}


1. Introduction

In this paper we examine the behavior of a firm that produces a product with a safety attribute. We assume that the firm knows whether its product is of high safety or low safety, where a safer product is one with a lower probability of causing harm. On the other hand, consumers of the product cannot observe directly the product's safety. Consumers can learn safety through one of two routes. The firm may, at a cost, disclose its safety prior to sale; alternatively, if a firm does not disclose its safety then consumers can attempt to infer its safety from the price charged. That is, consumers may learn the product's safety through disclosure or through signaling.

The liability system is important because it is a determinant of the firm's full marginal cost, which consists of both manufacturing cost and liability cost; this dependence of marginal cost on liability in turn affects the price and the output level for the firm, thereby influencing welfare. In particular, if the firm does not bear substantial liability for a consumer's harm, then the firm's marginal cost consists mainly of manufacturing cost, which is presumably higher for safer products. On the other hand, if the firm does bear substantial liability for a consumer's harm, then the firm's marginal cost consists of both manufacturing cost and liability cost. In this case, it is quite possible for a firm producing a safer product to have lower full marginal cost (the composition of marginal cost and its relationship to liability law will be discussed in detail below). We show that whether high safety is signaled with a higher or a lower price (than would occur under full information) depends critically upon whether the firm bears substantial liability for a consumer's harm. ${ }^{1}$

${ }^{1}$ Technically, when the firm's full marginal cost is increasing (decreasing) in safety, we find that the firm distorts its price upward (downward) to signal high safety. We showed this basic result for a continuum of types in Daughety and Reinganum, 1995, but that model did not allow for voluntary disclosure or for possibly-naive consumers. 
Since the safety of a firm's product is revealed - either through disclosure or through signaling - a welfare analysis of voluntary disclosure now focuses not on how much information is ultimately revealed, but whether it is revealed through the socially-optimal channel. A low-safety firm charges its full-information price and makes its full-information profits in a separating signaling equilibrium; consequently, a low-safety firm will never engage in disclosure for any positive disclosure cost. When the firm does not bear substantial liability for a consumer's harm, then in a separating signaling equilibrium the high-safety firm charges a higher price and sells less output than it would under full information (a fortiori, this is less than the socially-optimal output). Since the firm considers its own profit increase from disclosure, but not the value of the additional output to consumers, there will be a range of disclosure costs for which the high-safety firm inefficiently chooses to signal rather than disclose. In this parameter regime, a mandatory disclosure rule may be beneficial (this is discussed with more precision in Section 4). However, when the firm does bear substantial liability for a consumer's harm, then in a separating signaling equilibrium the high-safety

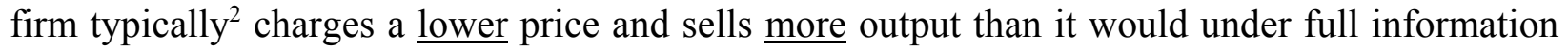
(though still less than the socially-optimal output). In this case, although there is a range of disclosure costs for which the high-safety firm will choose disclosure, any disclosure is welfareimpairing, even if the disclosure cost is zero. Thus, whether ex ante information regulation (in the form of mandatory disclosure) or reliance on ex post liability that induces information revelation is the better policy also depends upon whether the firm faces substantial liability for a consumer's harm.

2 We say "typically" because when the marginal cost of a low-safety unit is substantially higher than the marginal cost of a high-safety unit, then the firm with the high-safety product can signal without distorting its price away from the full-information level. 
Finally, we re-consider the analysis under the assumption that a small fraction of consumers are "naively optimistic:" while these consumers become informed when safety is disclosed, they do not update their beliefs about safety based on the product's price (following non-disclosure). Rather, they persistently believe that the product is of high quality, and purchase accordingly. We find that the presence of such consumers is beneficial not only to the low-safety firm, but also to the high-safety firm (since it need not engage in as much distortion in order to signal its safety). Since both firm types enjoy higher profits in the separating signaling equilibrium, incentives for voluntary disclosure are reduced by the presence of such consumers.

\section{Literature Review}

There is an extensive economics literature that deals with firms selling products whose quality is exogenous and known to the firms themselves, but is not observable to consumers prior to purchase. Two alternative conceptualizations of the problem have yielded two streams of research between which, to our knowledge, there is virtually no cross-talk. The two ${ }^{3}$ resulting literatures are (1) the disclosure literature, which assumes that a firm can credibly disclose its quality, perhaps at a cost; and (2) the signaling literature, which assumes that a firm cannot credibly disclose its quality and must rely on other strategies, most notably the price, that might convey information. The disclosure literature invariably makes an assumption which renders signaling

3 A third distinct approach to unobservable quality involves the idea of a "qualityguaranteeing price" (beginning with Klein and Leffler, 1981; see Bester, 1998, for a recent example and further references). In this literature, quality is endogenously-chosen by the firm after it posts its price. A firm that dilutes its quality will lose future sales, and a firm that charges too low a price will have an incentive to subsequently dilute quality. Understanding this, consumers will not buy at such prices. Instead, there is a threshold price that is high enough to make it optimal for the firm subsequently to provide high quality rather than to cash in now and forego future sales. Consumers will only be willing to buy at prices at or above this quality-guaranteeing price. 
impossible: the marginal cost of production is independent of quality. ${ }^{4}$ Thus, for these models, nondisclosure is consistent with all non-disclosing types charging the same price. ${ }^{5}$ Few signaling models of product quality assume that products of different quality are equally costly to produce. ${ }^{6}$ Most signaling models assume that higher-quality products are more costly, ${ }^{7}$ and some are agnostic on the issue, allowing higher-quality products to be either more or less costly. ${ }^{8}$ This difference in marginal costs allows the price chosen by the firm to reveal its product's quality.

Several previous papers develop models in which price signals product quality; such a model will appear as part of our analysis, but it will be augmented with a disclosure decision. Bagwell and Riordan (1991) provide a two-type model which is very similar to the one we use for our signaling subgame; the main difference is that we also allow full marginal cost to decrease in quality, which is envisioned in this paper as safety. Daughety and Reinganum (1995) provide a model with a continuum of types that permits marginal cost to be either increasing in safety or decreasing in safety; the signaling portion of our current model is essentially a two-type version of

${ }^{4}$ Most disclosure models do not consider liability cost for the firm; those that do consider it assume perfect compensation, so consumers do not care about quality (see, for example, Polinsky and Shavell, 2006).

${ }^{5}$ For examples of models which involve a single firm (or can be viewed as such due to a lack of strategic interaction), see Viscusi (1978), Grossman (1981), Milgrom (1981), Jovanovic (1982), Matthews and Postlewaite (1985), Milgrom and Roberts (1986b), Shavell (1994) and Polinsky and Shavell (2006). For examples involving multiple firms, see Board (2003), Cheong and Kim (2004), Levin, Peck and Ye (2005), and Hotz and Xiao (2005).

${ }^{6}$ But see Hertzendorf and Overgaard (2001a,b) for models that do make this assumption.

${ }^{7}$ Examples include Bagwell and Riordan (1991), Bagwell (1993), Shieh (1993), Fluet and Garella (2002), and Daughety and Reinganum (2005, 2007). 2005).

8 Examples include Milgrom and Roberts (1986a) and Daughety and Reinganum (1995, 
this model. Daughety and Reinganum (2005) provide a model with a continuum of types and unit demand; in that paper, the firm can commit to a disclosure policy before it learns its type, but cannot make a disclosure after learning its type. In the current paper, we model the disclosure decision as occurring after the firm has learned its type, consistent with the usual timing in the disclosure literature. ${ }^{9}$ Finally, in Daughety and Reinganum $(2005,2007)$, no disclosure is possible but multiple firms engage in price-quality signaling under the assumption that marginal cost is increasing in quality. ${ }^{10}$

On the disclosure side of the literature, Jovanovic (1982) and Polinsky and Shavell (2006) are perhaps the closest in certain attributes to our paper. Jovanovic assumes that a firm knows the quality of its own good, but disclosure is costly. Since marginal cost does not vary with quality, all firms that do not disclose receive the same price (that is, price cannot serve as a signal of quality following non-disclosure). Polinsky and Shavell (2006) examine a model in which firms that may face liability for harm can disclose quality information costlessly, but need not acquire it. They examine the usefulness of mandatory disclosure rules in this context, with particular emphasis on how they affect incentives to acquire information in the first place. Absent liability, if acquisition were costless then skeptical beliefs on the part of consumers would induce the firm to acquire information and then disclose it. But if information is costly to acquire, then a firm may not disclose its quality either because it does not know its quality, or because it knows its quality is low (a firm

9 One exception is Levin, Peck and Ye (2005), who consider both alternatives: (1) the disclosure decision is made before the firm learns its product quality; and (2) the disclosure decision is made after the firm learns its product quality.

10 Arlen and Bunting (2006) ask whether voluntary contracting over liability can signal quality when price is competitively determined. 
which learns that its product is of high quality will disclose this). Again, since marginal cost does not vary with quality, price cannot serve as a signal of quality following non-disclosure. Polinsky and Shavell then consider liability under both a negligence standard and strict liability. Since the firm will meet the standard of care in a negligence regime, this will reduce to the previous analysis in which the consumer bears all of the loss (and, since liability costs are zero, the firm's marginal cost does not vary with quality). When the firm faces strict liability, then its marginal liability costs must vary with quality, but in this case Polinsky and Shavell assume that the consumer is fullycompensated and hence she no longer cares about quality (and the firm no longer cares about disclosure).

In our model, the acquisition of information is costless but its disclosure is costly, and thus some firm types will not disclose (as in Jovanovic, 1982). However, because marginal cost varies with safety (and because consumers still bear some of the loss, so they care about safety), the firm's price will serve as a signal of its product's safety following non-disclosure. Thus, our assessment of the value of mandatory disclosure focuses not on the amount of information that is ultimately provided, but on whether it is provided through the socially-optimal channel (e.g., disclosure or signaling). ${ }^{11}$

The only published paper of which we are aware that involves both disclosure and signaling is Fishman and Hagerty (2003). ${ }^{12,13}$ However, in their model disclosure and signaling are not

11 In a companion paper, "Communicating Quality: A Unified Model of Disclosure and Signaling" (Daughety and Reinganum, 2006), we examine a version of the signaling-versusdisclosure model with a continuum of quality levels; however, that paper does not consider firm liability for losses nor does it consider the effects of naive consumers on pricing and disclosure.

12 Since completing this paper, we have become aware of a working paper by Caldieraro, Shin and Stivers (2007) that assumes one high-quality and one low-quality firm (firms know each 


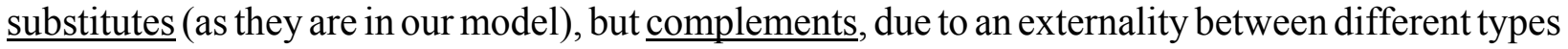
of consumers. Thus, signaling does not accompany non-disclosure in their model (because they maintain the crucial assumption that marginal cost is the same for high- and low-quality products); it can only accompany disclosure. ${ }^{14}$ Our model is very different from that of Fishman and Hagerty (2003) in that all consumers become informed about safety when the firm discloses it; moreover, our consumers have downward-sloping demand. Our firm has a marginal cost that is safetydependent, though it may be increasing or decreasing in safety. Thus, if a firm does not disclose its safety directly, it reveals it through its price: disclosure and signaling are substitutes.

\section{Plan of the Paper}

In Section 2, we describe the model set-up and notation. Section 3 characterizes equilibrium pricing with and without disclosure. Section 4 compares equilibrium disclosure with sociallyoptimal disclosure and considers the desirability of mandatory disclosure rules. Section 5 modifies

others' qualities; consumers cannot observe quality directly). After firms individually choose whether or not to disclose, only some consumers observe the disclosure, leading to both disclosure and signaling by the firms. Even though disclosure is free, consumers cannot induce "unraveling" as they cannot employ skeptical beliefs.

13 A related paper from the auction literature is Cai, Riley and Ye (forthcoming). A seller with private info regarding her own valuation auctions an item to multiple potential buyers, whose valuations are positively-correlated with that of the seller. The seller's reserve price signals her value to the buyers but signaling involves distortion. In the working paper version, the authors briefly discuss an application involving costly external value certification.

${ }^{14}$ This occurs because they assume two different types of consumer, each of which demands one unit; one type of consumer becomes "informed" about quality when a disclosure is made, while the other remains "uninformed" about actual quality, but is aware that a disclosure has been made. In this setting, an "uninformed" consumer can draw an inference from the firm's price about its quality. To see how this can happen, suppose that most consumers are capable of becoming "informed." Then a firm which makes a disclosure and charges a high price will only do so if it is a high-quality firm, for if it were a low-quality firm charging a high price, it would alienate all of the informed consumers. So an uninformed consumer who knows that a disclosure was made (but not its content) can infer from a high price that the firm has a high-quality product. 
the preceding analysis to incorporate naive consumers who do not apply the skeptical beliefs that are integral to both signaling and disclosure models. While these consumers become informed when safety is disclosed, they do not update their beliefs about safety based on the product's price (following non-disclosure), but persistently believe that the product is of high safety. We analyze such a case because we expect it is the one that is most worrisome to those considering disclosure policy in consumer-goods markets. Section 6 summarizes and suggests some possible extensions. Extensive derivations are provided in the Appendix.

\section{Model Set-up}

\section{Safety}

Assume that a single firm produces a product that may be of either high $(\mathrm{H})$ safety or low (L) safety; let $\lambda \in(0,1)$ denote the probability that the product is of high safety. Safety itself takes the form of a probability that the consumer is not harmed by the product. Let $\theta_{\mathrm{i}}$ represent the probability that the consumer is not harmed by the product of type $i \in\{H, L\}$, where $1>\theta_{H}>\theta_{L}>$ 0. Thus, either type of product may be used without harm in a given instance of its consumption, but either type of product may also cause harm in a given instance; the key attribute is that highersafety products are more likely to be used without harm.

\section{Liability}

When use of the product causes harm, a loss is created; this loss includes the actual harm experienced by the consumer, plus any costs associated with settlement or trial. The liability system allocates the loss between the consumer and the firm, by specifying how much compensation is due 
to the consumer from the firm, and under what circumstances. ${ }^{15}$ For instance, assuming strict liability, the firm is responsible for the consumer's harm, but each party is responsible for her own legal costs. Moreover, it may be difficult for the plaintiff to establish causation in a given instance. Thus, we expect that consumers will bear some residual loss, and we denote the uncompensated loss to the consumer by $\delta>0$. We denote the firm's anticipated liability payment in the event of harm by $\gamma>0$; thus, the total loss is given by $\mathrm{T}=\delta+\gamma$.

\section{Consumers}

Both types of product provide utility to the consumer, but a unit that fails provides less utility. In particular, assume that the consumer's utility is quadratic in the quantity consumed of the product of interest, with the coefficient on the quadratic term denoted $\beta$, and the coefficient on the linear term denoted $\alpha$ in the case of a unit that does not cause harm and $\alpha-\delta$ in the case of a unit that fails, causing the consumer to bear the loss $\delta$. The consumer may or may not be able to observe directly the product's safety before purchase. Let the perceived safety of the good be denoted $\widetilde{\theta}$. If the product's safety is observable before purchase (e.g., because the firm discloses it), then $\widetilde{\theta}=$ $\theta_{\mathrm{i}}$, for $\mathrm{i} \in\{\mathrm{H}, \mathrm{L}\}$; on the other hand, if the product's safety is not observable before purchase, then these perceptions will be determined as part of a perfect Bayesian equilibrium.

The consumer's utility function is quasi-linear in all other goods; thus, if the price of the product is $\mathrm{p}$, the consumer's income is I, and she consumes q units of the good with perceived safety

15 When a consumer is physically (or emotionally) harmed, the liability system supersedes any contractual liability such as a warranty (which might otherwise serve as a signal of safety). Most warranties offer very limited compensation, such as repair or replacement of the item. Moreover, the extent of contractual liability that must be assumed in order to signal safety would typically exceed the expected harm, and thus might run afoul of the penalty doctrine. Under the penalty doctrine, the common law does not enforce stipulated damages in excess of expected damages (Rea, 1998, p. 24). 
$\widetilde{\theta}$, then her utility is given by:

$$
\mathrm{U}(\mathrm{p}, \mathrm{q}, \widetilde{\theta}) \equiv[\alpha-(1-\widetilde{\theta}) \delta] \mathrm{q}-\beta(\mathrm{q})^{2} / 2+\mathrm{I}-\mathrm{pq} .
$$

Therefore, the consumer's demand for the product of perceived quality $\widetilde{\theta}$ is given by:

$$
\mathrm{q}(\mathrm{p}, \widetilde{\theta})=[\alpha-(1-\widetilde{\theta}) \delta-\mathrm{p}] / \beta .
$$

Note that the quantity demanded is an increasing function of perceived quality.

\section{The Firm}

The firm of type i manufactures units of the product at a constant marginal cost of $c\left(\theta_{i}\right), i \in$ $\{\mathrm{H}, \mathrm{L}\}$. This cost consists of marginal manufacturing cost, denoted $\mathrm{k} \theta_{\mathrm{i}}$, which is increasing in safety (that is, safer products cost more to produce) and marginal expected liability cost, denoted $\gamma\left(1-\theta_{\mathrm{i}}\right)$, which is decreasing in safety (that is, safer products generate lower expected liability cost). Thus, $\mathrm{c}\left(\theta_{\mathrm{i}}\right)=\mathrm{k} \theta_{\mathrm{i}}+\gamma\left(1-\theta_{\mathrm{i}}\right)$ is the firm's full marginal cost; the firm's full marginal cost is increasing in safety if $\mathrm{k}>\gamma$, and decreasing in safety if $\mathrm{k}<\gamma$. If the firm does not bear substantial liability for a consumer's harm, then $\gamma$ will be small and thus $\mathrm{k}>\gamma$. On the other hand, if the firm does bear substantial liability for a consumer's harm, then $\gamma$ will be large and thus $\mathrm{k}<\gamma .{ }^{16}$

The gross profits for the firm depend on its true price-cost margin and consumer demand, which depends on perceived safety:

$$
\pi\left(\mathrm{p}, \theta_{\mathrm{i}}, \widetilde{\theta}\right) \equiv\left(\mathrm{p}-\mathrm{c}\left(\theta_{\mathrm{i}}\right)\right)[\alpha-(1-\widetilde{\theta}) \delta-\mathrm{p}] / \beta .
$$

The firm of type i can affect its perceived safety in two ways, through its disclosure policy and its price. If the firm elects to disclose its safety, then $\widetilde{\theta}=\theta_{\mathrm{i}}$. We assume that disclosure requires

${ }^{16}$ We specifically rule out the knife-edge case of $\mathrm{k}=\gamma$, since this implies that marginal cost is the same for both levels of safety. In this case, price cannot serve as a signal of safety and we are back in the traditional disclosure model in which non-disclosure results in all non-disclosing types charging the same price. 
a cost of $\mathrm{D}>0$; this reflects the need for verification of the firm's type by some independent third party. This verification could be achieved by testing a sample of units, or by surveying a sample of consumers about their experiences (without providing them any reward that is contingent on their answers). If the firm elects not to disclose its safety, consumers will base their perceptions of safety on the accompanying price. We model the choice of disclosure policy and price as being simultaneous, once the firm has learned its true type.

Finally, let $\mathrm{c}_{\mathrm{i}} \equiv \mathrm{c}\left(\theta_{\mathrm{i}}\right)$ and $\alpha_{\mathrm{i}} \equiv \alpha-\left(1-\theta_{\mathrm{i}}\right) \delta$. Then $\alpha_{\mathrm{H}}-\alpha_{\mathrm{L}}=\delta\left(\theta_{\mathrm{H}}-\theta_{\mathrm{L}}\right)>0$, and $\mathrm{c}_{\mathrm{H}}-\mathrm{c}_{\mathrm{L}}=(\mathrm{k}-$ $\gamma)\left(\theta_{\mathrm{H}}-\theta_{\mathrm{L}}\right)(>=<) 0$ as $\mathrm{k}(>=<) \gamma$. The following parameter restrictions will be maintained throughout the paper.

Assumption 1. $\quad \alpha_{\mathrm{H}}-\mathrm{c}_{\mathrm{H}}>\alpha_{\mathrm{L}}-\mathrm{c}_{\mathrm{L}}$.

Assumption 2. $\alpha_{\mathrm{L}}>\max \left\{\mathrm{c}_{\mathrm{H}}, \mathrm{c}_{\mathrm{L}}\right\}$.

Assumption 1 implies that the high-safety product is socially-preferred to the low-safety product (even though the high-safety product is more costly to produce). Alternatively put, Assumption 1 implies that the combined loss from an accident $(\delta+\gamma)$ exceeds the incremental production cost of improving safety $(\mathrm{k})$. Assumption 2 ensures that both firm types can make positive profits, whether they are correctly-perceived or mis- perceived as the other type (since $\alpha_{\mathrm{H}}$ $>\alpha_{L}$, it follows from Assumption 2 that $\alpha_{H}>\max \left\{c_{H}, c_{L}\right\}$ as well). Another implication of Assumption 2 is that both products are socially-beneficial; consumers might, in principle, over-pay for a unit, but neither product type generates negative expected surplus.

\section{Equilibrium Pricing With and Without Disclosure}

In this section, we first characterize the equilibrium pricing behavior that accompanies a 
decision to disclose safety directly. Next, we characterize equilibrium pricing behavior when the disclosure cost $\mathrm{D}$ is prohibitively high; this involves solving a relatively straightforward signaling model in which price reveals safety. In Section 4, we lower the disclosure cost to determine which types, if any, will defect from signaling to the outside option of direct disclosure.

Note that any firm type that discloses can (and will) charge its full-information monopoly price (that is, the price it would charge if consumers could observe safety directly). Let $\mathrm{P}_{\mathrm{i}}^{\mathrm{f}}$ denote the full-information monopoly price for a firm producing a product of type $i$, and let $\Pi_{i}^{f}$ denote the corresponding full-information monopoly profits. Then $\mathrm{P}_{\mathrm{i}}^{\mathrm{f}}=\left(\alpha_{\mathrm{i}}+\mathrm{c}_{\mathrm{i}}\right) / 2$ and $\Pi_{\mathrm{i}}^{\mathrm{f}}=\left(\alpha_{\mathrm{i}}-\mathrm{c}_{\mathrm{i}}\right)^{2} / 4 \beta$. Now let $\mathrm{P}_{\mathrm{i}}^{\mathrm{d}}$ denote the equilibrium price that accompanies disclosure for a firm producing a product of type $\mathrm{i}$, and let $\Pi_{\mathrm{i}}^{\mathrm{d}}$ denote the corresponding equilibrium profits. Since disclosure is costly, but the pricing game accompanying disclosure is one of full information, the equilibrium price and payoff for a disclosing firm of type i are simply $\mathrm{P}_{i}^{\mathrm{d}}=\mathrm{P}_{\mathrm{i}}^{\mathrm{f}}$ and $\prod_{i}^{\mathrm{d}}=\prod_{\mathrm{i}}^{\mathrm{f}}-\mathrm{D}, \mathrm{i} \in\{\mathrm{H}, \mathrm{L}\}$.

Now suppose that the disclosure cost $\mathrm{D}$ is prohibitively high, so it is common knowledge that no firm type will choose disclosure. Then consumers will try to infer product safety from the price that is being charged. We will characterize a (refined) separating perfect Bayesian equilibrium in which price serves as a signal of safety. ${ }^{17}$ Let $\mathrm{B}(\mathrm{p})$ be the belief function that relates the firm's price to the consumer's perceived safety; thus, if the firm charges the price $p$, then it is inferred to have safety $\mathrm{B}(\mathrm{p}) \in\left\{\theta_{\mathrm{H}}, \theta_{\mathrm{L}}\right\}$. A firm charging price $\mathrm{p}$, with true safety $\theta_{\mathrm{i}}$ and perceived safety $\widetilde{\theta}=\mathrm{B}(\mathrm{p})$, obtains profit of $\pi\left(\mathrm{p}, \theta_{\mathrm{i}}, \mathrm{B}(\mathrm{p})\right) \equiv\left(\mathrm{p}-\mathrm{c}\left(\theta_{\mathrm{i}}\right)\right)[\alpha-(1-\mathrm{B}(\mathrm{p})) \delta-\mathrm{p}] / \beta$. In addition to incentive compatibility constraints that ensure separation, a separating perfect Bayesian equilibrium requires

${ }^{17}$ Although there exists a continuum of separating equilibria, the Intuitive Criterion (Cho and Kreps, 1987) selects a unique one; see the Appendix for details. Similarly, although pooling equilibria exist, they do not survive refinement using the Intuitive Criterion (see the Appendix). 
that consumers infer correctly the firm's type from its price; that is, the beliefs must be consistent with equilibrium play. Let $\mathrm{P}_{\mathrm{H}}^{\mathrm{s}}$ and $\mathrm{P}_{\mathrm{L}}^{\mathrm{s}}$ denote the equilibrium prices for a high-safety firm and a lowsafety firm, respectively, in a separating perfect Bayesian equilibrium and let $\Pi_{\mathrm{H}}^{\mathrm{s}}$ and $\Pi_{\mathrm{L}}^{\mathrm{s}}$ denote the corresponding equilibrium profits.

Definition 1. Suppose that D is prohibitively high, so neither firm type discloses. A separating perfect Bayesian equilibrium in prices consists of a pair of prices $\left(\mathrm{P}_{\mathrm{H}}^{\mathrm{s}}, \mathrm{P}_{\mathrm{L}}^{\mathrm{s}}\right)$, with $\mathrm{P}_{\mathrm{H}}^{\mathrm{s}} \neq \mathrm{P}_{\mathrm{L}}^{\mathrm{s}}$, and beliefs $B^{*}(p)$ such that:

(i) $\pi\left(\mathrm{P}_{\mathrm{H}}^{\mathrm{s}}, \theta_{\mathrm{H}}, \theta_{\mathrm{H}}\right) \geq \max _{\mathrm{p}} \pi\left(\mathrm{p}, \theta_{\mathrm{H}}, \mathrm{B}^{*}(\mathrm{p})\right)$;

(ii) $\pi\left(\mathrm{P}_{\mathrm{L}}^{\mathrm{s}}, \theta_{\mathrm{L}}, \theta_{\mathrm{L}}\right) \geq \max _{\mathrm{p}} \pi\left(\mathrm{p}, \theta_{\mathrm{L}}, \mathrm{B}^{*}(\mathrm{p})\right)$;

(iii) $\mathrm{B}^{*}\left(\mathrm{P}_{\mathrm{H}}^{\mathrm{s}}\right)=\theta_{\mathrm{H}}, \mathrm{B}^{*}\left(\mathrm{P}_{\mathrm{L}}^{\mathrm{s}}\right)=\theta_{\mathrm{L}}$.

(Consistency)

The following proposition is proved in the Appendix.

Proposition 1. There is a unique (refined) separating perfect Bayesian equilibrium in prices:

(i) the low-safety firm always charges its full-information price, $\mathrm{P}_{\mathrm{L}}^{\mathrm{s}}=\left(\alpha_{\mathrm{L}}+\mathrm{c}_{\mathrm{L}}\right) / 2$;

(ii) when $\mathrm{c}_{\mathrm{H}}>\mathrm{c}_{\mathrm{L}}$, then $\mathrm{P}_{\mathrm{H}}^{\mathrm{s}}=.5\left(\alpha_{\mathrm{H}}+\mathrm{c}_{\mathrm{L}}+\left\{\left(\alpha_{\mathrm{H}}-\mathrm{c}_{\mathrm{L}}\right)^{2}-\left(\alpha_{\mathrm{L}}-\mathrm{c}_{\mathrm{L}}\right)^{2}\right\}^{1 / 2}\right)>\mathrm{P}_{\mathrm{H}}^{\mathrm{f}}$; the beliefs supporting this equilibrium are $\mathrm{B}(\mathrm{p})=\theta_{\mathrm{L}}$ when $\mathrm{p}<\mathrm{P}_{\mathrm{H}}^{\mathrm{s}}$ and $\mathrm{B}(\mathrm{p})=\theta_{\mathrm{H}}$ when $\mathrm{p} \geq \mathrm{P}_{\mathrm{H}}^{\mathrm{s}}$; (iii) when $\mathrm{c}_{\mathrm{L}}>\mathrm{c}_{\mathrm{H}}$, then $\mathrm{P}_{\mathrm{H}}^{\mathrm{s}}=\min \left\{.5\left(\alpha_{\mathrm{H}}+\mathrm{c}_{\mathrm{L}}-\left\{\left(\alpha_{\mathrm{H}}-\mathrm{c}_{\mathrm{L}}\right)^{2}-\left(\alpha_{\mathrm{L}}-\mathrm{c}_{\mathrm{L}}\right)^{2}\right\}^{1 / 2}\right), \mathrm{P}_{\mathrm{H}}^{\mathrm{f}}\right\} \leq \mathrm{P}_{\mathrm{H}}^{\mathrm{f}}$; the supporting beliefs are $\mathrm{B}(\mathrm{p})=\theta_{\mathrm{L}}$ when $\mathrm{p}>\mathrm{P}_{\mathrm{H}}^{\mathrm{s}}$ and $\mathrm{B}(\mathrm{p})=\theta_{\mathrm{H}}$ when $\mathrm{p} \leq \mathrm{P}_{\mathrm{H}}^{\mathrm{s}}$.

It is worth noting that, even when the high-safety firm's price is distorted, it still belongs to the interval $\left(c_{\mathrm{H}}, \alpha_{\mathrm{H}}\right)$, so both the price-cost margin and equilibrium output are positive.

The intuition for the structure of this equilibrium is as follows. First, since it will be revealed in a separating equilibrium, the low-safety firm can do no better than to price at its full-information price and obtain its full-information profits. Second, in order to ensure separation, the high-safety 
firm must choose a price that a low-safety firm would not mimic. When the firm does not bear substantial liability for a consumer's harm, then $\gamma$ is small and $k-\gamma>0$, implying that ${ }^{18} c_{H}-c_{L}>0$. Thus, the proposition says that when the firm does not bear substantial liability for a consumer's harm, then the high-safety firm signals its safety by distorting its price upward from its fullinformation price. Increasing its price (and thus foregoing some sales) is less expensive for the highsafety firm than it is for the low-safety firm, because the low-safety firm has the larger price-cost margin for any given price and hence loses more than the high-safety firm on each foregone sale. There is a high enough price $\mathrm{P}_{\mathrm{H}}^{\mathrm{s}}$ (and thus a low enough sales volume) that makes the low-safety firm indifferent between mimicry and accepting its full-information profits. ${ }^{19}$

On the other hand, when the firm bears substantial liability for a consumer's harm, then $\gamma$ is large and $\gamma-k>0$, implying that $c_{L}-c_{H}>0$. We will refer to the cost difference $c_{L}-c_{H}$, which measures the low-quality product's cost disadvantage, as "moderate" when $\left(c_{L}-c_{H}\right)^{2}<\left(\alpha_{H}-\alpha_{L}\right)\left(\alpha_{H}\right.$ $\left.+\alpha_{L}-2 c_{L}\right)$, and as "large" when $\left(c_{L}-c_{H}\right)^{2} \geq\left(\alpha_{H}-\alpha_{L}\right)\left(\alpha_{H}+\alpha_{L}-2 c_{L}\right)$. The proposition indicates that when the cost difference $c_{L}-c_{H}$ is moderate, ${ }^{20}$ then the high-safety firm must distort its price downward from its full-information value. Downward distortion can deter mimicry because a price decrease (which increases sales) is less attractive for a low-safety firm than for a high-safety firm since the low-safety firm now has a lower price-cost margin for any given price. There is a low

${ }^{18}$ Recall that $\mathrm{c}_{\mathrm{H}}-\mathrm{c}_{\mathrm{L}}=(\mathrm{k}-\gamma)\left(\theta_{\mathrm{H}}-\theta_{\mathrm{L}}\right)(>=<) 0$ as $\mathrm{k}(>=<) \gamma$.

19 As is shown in the Appendix, the H-type firm would prefer to charge $\mathrm{P}_{\mathrm{H}}^{\mathrm{s}}$ and be recognized as an H-type than to choose its best alternative price and be taken for an L-type. Mimicry by the L-type firm can also be deterred by a downward-distorted price but the H-type firm would rather give up and be taken for an L-type than to use such a price to distinguish itself.

${ }^{20}$ A sufficient condition for this cost disadvantage to be moderate is that the high-safety firm's full-information price is higher than that of the low-safety firm: that is, $\mathrm{P}_{\mathrm{H}}^{\mathrm{f}}=\left(\alpha_{\mathrm{H}}+\mathrm{c}_{\mathrm{H}}\right) / 2>\left(\alpha_{\mathrm{L}}\right.$ $\left.+\mathrm{c}_{\mathrm{L}}\right) / 2=\mathrm{P}_{\mathrm{L}}^{\mathrm{f}}$ or, equivalently, $\gamma-\mathrm{k}<\delta$. 
enough price $\mathrm{P}_{\mathrm{H}}^{\mathrm{s}}$ that makes the low-safety firm indifferent between mimicry and accepting its fullinformation profits. ${ }^{21}$ When the cost difference $c_{L}-c_{H}$ is large, then the high-safety firm need not distort its price in order to be recognized; its full-information price is already so low that the lowsafety firm does not want to mimic it, even if doing so would result in an inference of high safety.

\section{Equilibrium and Socially-Optimal Disclosure}

An immediate implication of Proposition 1 is that the high-safety firm suffers a loss in profit due to private information: that is, $\Pi_{\mathrm{H}}^{\mathrm{f}}-\Pi_{\mathrm{H}}^{\mathrm{s}}$ is positive (unless the low-safety product's cost disadvantage is large, in which case $\prod_{\mathrm{H}}^{\mathrm{f}}-\Pi_{\mathrm{H}}^{\mathrm{s}}=0$ ), while the low-safety firm suffers no loss: that is, $\Pi_{\mathrm{L}}^{\mathrm{f}}-\Pi_{\mathrm{L}}^{\mathrm{s}}=0$. Thus, as the disclosure cost $\mathrm{D}$ is lowered from its prohibitively high level, it is the high-safety firm that will first defect from the signaling equilibrium to the outside option of direct disclosure: a high-safety firm will choose to disclose when $\mathrm{D} \leq \Pi_{\mathrm{H}}^{\mathrm{f}}-\Pi_{\mathrm{H}}^{\mathrm{s}}$. Since the low-safety firm's payoff will continue to be the same regardless of the high-safety firm's decision to disclose (the low-safety firm will continue to choose its full-information monopoly price), the low-safety firm continues to eschew disclosure. Only at $\mathrm{D}=0$ does the low-safety firm become indifferent between disclosing and not disclosing (and similarly for the high-safety firm when the low-safety product's cost disadvantage is large). These results are summarized in the following proposition.

Proposition 2. (i) A low-safety firm will not disclose for any D $>0$.

(ii) When $c_{H}>c_{L}$, or when $c_{L}>c_{H}$ but this cost difference is moderate, there is a range of

21 As is shown in the Appendix, the H-type firm would prefer to charge $\mathrm{P}_{\mathrm{H}}^{\mathrm{s}}$ and be recognized as an H-type than to choose its best alternative price and be taken for an L-type. Mimicry by the L-type firm can also be deterred by an upward-distorted price but the H-type firm would rather give up and be taken for an L-type than to use such a price to distinguish itself. 
disclosure costs $\mathrm{D} \in\left(0, \Pi_{\mathrm{H}}^{\mathrm{f}}-\Pi_{\mathrm{H}}^{\mathrm{s}}\right)$, for which the high-safety firm will disclose;

(iii) When $c_{L}>c_{H}$ and this cost difference is large, then a high-safety firm will not disclose for any $\mathrm{D}>0$.

\section{Welfare Analysis of Voluntary Disclosure}

As was mentioned in the Introduction, when marginal cost varies with safety the alternative to disclosure is not "non-disclosure," but signaling: both firms' types are ultimately revealed, but possibly through different channels. A welfare analysis of disclosure then rests not on the amount of information that is ultimately provided, but on whether it is provided through the socially-optimal channel. The firm pays a lump-sum cost associated with disclosure, while the firm's cost of signaling sometimes involves distortions in pricing and output. Although the lump-sum cost of disclosure affects total surplus in the same way as it affects profits (that is, via simple subtraction), distortions in pricing and output can affect firm profits and consumer or total surplus in very different ways.

In a regime of voluntary disclosure, the low-safety firm does not engage in costly disclosure, because signaling entails no cost. Thus, the private and social incentives to disclose coincide for the low-safety firm. A comparison of the high-safety firm's incentives to disclose with the social incentives requires a comparison of output levels; let $\mathrm{Q}_{\mathrm{H}}^{\mathrm{s}}, \mathrm{Q}_{\mathrm{H}}^{\mathrm{f}}$, and $\mathrm{Q}_{\mathrm{H}}^{\mathrm{o}}$ denote the output of the highsafety firm in the signaling equilibrium, under full information, and at the social optimum, respectively. ${ }^{22}$ Since the signaling price $\mathrm{P}_{\mathrm{H}}^{\mathrm{s}} \in\left(\mathrm{c}_{\mathrm{H}}, \alpha_{\mathrm{H}}\right)$, it is straightforward to show that if $\mathrm{c}_{\mathrm{H}}>\mathrm{c}_{\mathrm{L}}$ (that is, if the firm does not bear substantial liability for a consumer's harm) then $\mathrm{Q}_{\mathrm{H}}^{\mathrm{s}}<\mathrm{Q}_{\mathrm{H}}^{\mathrm{f}}<\mathrm{Q}_{\mathrm{H}}^{\circ}$.

\footnotetext{
${ }^{22}$ These outputs are given by $\mathrm{Q}_{\mathrm{i}}^{\mathrm{s}}=\left[\alpha-\left(1-\widetilde{\theta}_{\mathrm{i}}\right) \delta-\mathrm{P}_{\mathrm{i}}^{\mathrm{s}}\right] / \beta ; \mathrm{Q}_{\mathrm{i}}^{\mathrm{f}}=\left[\alpha-\left(1-\widetilde{\theta}_{\mathrm{i}}\right) \delta-\mathrm{P}_{\mathrm{i}}^{\mathrm{f}} / / \beta\right.$; and $\mathrm{Q}_{\mathrm{i}}^{\mathrm{o}}=$ $\left[\alpha-\left(1-\widetilde{\theta}_{\mathrm{i}}\right) \delta-\mathrm{c}\left(\widetilde{\theta}_{\mathrm{i}}\right)\right] / \beta$, for $\mathrm{i} \in\{\mathrm{H}, \mathrm{L}\}$.
} 
Thus, both profits and consumer surplus ${ }^{23}$ (and hence total surplus, ${ }^{24}$ denoted $\mathrm{S}_{\mathrm{i}}^{\mathrm{t}}$, where $\mathrm{i}=\mathrm{H}$ or $\mathrm{L}$ and $\mathrm{t}=\mathrm{s}$, $\mathrm{f}$, or $\mathrm{o}$ as appropriate) will be higher under full information than under signaling, since full information results in greater output (though still less than the socially-optimal amount). Since the firm incorporates only the effect on profits in making its disclosure decision, there will exist values of the disclosure cost $\mathrm{D}$ for which the firm will choose not to disclose when it would be socially optimal for it to do so (i.e., $\Pi_{\mathrm{H}}^{\mathrm{f}}-\Pi_{\mathrm{H}}^{\mathrm{s}}<\mathrm{D}<\mathrm{S}_{\mathrm{H}}^{\mathrm{f}}-\mathrm{S}_{\mathrm{H}}^{\mathrm{s}}$ ).

If $c_{L}-c_{H}>0$ (that is, if the firm bears substantial liability for a consumer's harm) and the low-safety product's cost disadvantage $\mathrm{c}_{\mathrm{L}}-\mathrm{c}_{\mathrm{H}}$ is large, then $\mathrm{Q}_{\mathrm{H}}^{\mathrm{s}}=\mathrm{Q}_{\mathrm{H}}^{\mathrm{f}}<\mathrm{Q}_{\mathrm{H}}^{\circ}$. In this case, the private and social incentives for disclosure again coincide, since the high-safety firm will not disclose for any $\mathrm{D}>0$, and this is socially optimal (because, in this case, the high-safety firm need not distort its price and output to reveal safety). However, if $c_{L}-c_{H}>0$ and the low-safety product's cost disadvantage $c_{L}-c_{H}$ is moderate, then it is straightforward to show that $\mathrm{Q}_{\mathrm{H}}^{\mathrm{f}}<\mathrm{Q}_{\mathrm{H}}^{\mathrm{s}}<\mathrm{Q}_{\mathrm{H}}^{\circ}$. In this case, signaling requires the firm to lower its price and expand its output relative to the full-information monopoly levels, which provides a benefit to consumers and an increase in total surplus. Thus, when $\mathrm{c}_{\mathrm{L}}-\mathrm{c}_{\mathrm{H}}>0$ consumers (and a social planner) would always prefer information transmission to occur through signaling rather than disclosure. Clearly there are values of the disclosure cost $\mathrm{D}>$ 0 for which the firm also prefers signaling to disclosure, but there are also values of $\mathrm{D}>0$ for which the firm can improve its profits by disclosing (since it can then raise its price and reduce its output to coincide with the full-information monopoly optimum). This disclosure is socially excessive,

${ }^{23}$ Consumer surplus is given by $\mathrm{CS}_{\mathrm{i}}^{\mathrm{s}}=\left[\alpha-\left(1-\widetilde{\theta}_{\mathrm{i}}\right) \delta-\mathrm{P}_{\mathrm{i}}^{\mathrm{s}}\right]^{2} / 2 \beta ; \mathrm{CS}_{\mathrm{i}}^{\mathrm{f}}=\left[\alpha-\left(1-\widetilde{\theta}_{\mathrm{i}}\right) \delta-\mathrm{P}_{\mathrm{j}}^{\mathrm{f}}\right]^{2} / 2 \beta ;$ and $\mathrm{CS}_{\mathrm{i}}^{\mathrm{o}}=\left[\alpha-\left(1-\widetilde{\theta}_{\mathrm{i}}\right) \delta-\mathrm{c}\left(\widetilde{\theta}_{\mathrm{i}}\right)\right]^{2} / 2 \beta$, for $\mathrm{i} \in\{\mathrm{H}, \mathrm{L}\}$.

${ }^{24}$ Total surplus is given by $\mathrm{S}_{\mathrm{i}}^{\mathrm{s}}=\mathrm{CS}_{\mathrm{i}}^{\mathrm{s}}+\prod_{\mathrm{i}}^{\mathrm{s}} ; \mathrm{S}_{\mathrm{i}}^{\mathrm{f}}=\mathrm{CS}_{\mathrm{i}}^{\mathrm{f}}+\prod_{\mathrm{i}}^{\mathrm{f}}$, and $\mathrm{S}_{\mathrm{i}}^{\mathrm{o}}=\mathrm{CS}_{\mathrm{i}}^{o}+\Pi_{\mathrm{i}}^{\mathrm{o}}$, for $\mathrm{i} \in\{\mathrm{H}, \mathrm{L}\}$. 
even if it is free.

\section{Mandatory Disclosure}

The foregoing indicates that there may be too little disclosure when the firm does not bear substantial liability for a consumer's harm (i.e., when $c_{H}>c_{L}$ ), while there may be too much disclosure when the firm does bear substantial liability for a consumer's harm (i.e., when $c_{L}>c_{H}$, but this difference is moderate). Thus, the only parametric regime in which mandatory disclosure could play a positive role is when $\mathrm{c}_{\mathrm{H}}>\mathrm{c}_{\mathrm{L}}$ and $\mathrm{D} \in\left(\Pi_{\mathrm{H}}^{\mathrm{f}}-\Pi_{\mathrm{H}}^{\mathrm{s}}, \mathrm{S}_{\mathrm{H}}^{\mathrm{f}}-\mathrm{S}_{\mathrm{H}}^{\mathrm{s}}\right)$. Since a mandatory disclosure rule yields benefits only when product safety is high but imposes the disclosure cost in either state, the expected social benefits of such a rule are $\lambda\left(\mathrm{S}_{\mathrm{H}}^{\mathrm{f}}-\mathrm{S}_{\mathrm{H}}^{\mathrm{s}}\right)-\mathrm{D}$; assuming that the firm bears the cost $\mathrm{D}$, any benefits of mandatory disclosure accrue to consumers (because, by hypothesis, $\mathrm{D}>\prod_{\mathrm{H}}^{\mathrm{f}}-\prod_{\mathrm{H}}^{\mathrm{s}}$ ).

This suggests that mandatory disclosure requirements are most likely to be beneficial in markets wherein safety is likely to be high (i.e., $\lambda$ is high), but safer units are more costly to manufacture and the firm does not bear substantial liability for a consumer's harm (i.e., $c_{H}>c_{L}$ ), and the disclosure cost is neither too high nor too low (i.e., $\left.\mathrm{D} \in\left(\prod_{\mathrm{H}}^{\mathrm{f}}-\Pi_{\mathrm{H}}^{\mathrm{s}}, \mathrm{S}_{\mathrm{H}}^{\mathrm{f}}-\mathrm{S}_{\mathrm{H}}^{\mathrm{s}}\right)\right)$.

\section{The Effect of Naively Optimistic Consumers}

This section will incorporate a small fraction, denoted $\varepsilon$, of consumers who are "naive" in the sense that they do not apply the skeptical beliefs that are integral to both signaling and disclosure models. In what follows, we will indicate with a "^" those expressions that change due to the inclusion of naive consumers. Wherever the expression in question remains unchanged, we will omit the "^" to emphasize that it is unchanged. We assume that these consumers do become informed when the firm elects to disclose its safety, and thus the full-information prices and profits 
remain as before: $\mathrm{P}_{\mathrm{i}}^{\mathrm{f}}=\left(\alpha_{\mathrm{i}}+\mathrm{c}_{\mathrm{i}}\right) / 2$ and $\Pi_{\mathrm{i}}^{\mathrm{f}}=\left(\alpha_{\mathrm{i}}-\mathrm{c}_{\mathrm{i}}\right)^{2} / 4 \beta, \mathrm{i} \in\{\mathrm{H}, \mathrm{L}\}$, where $\alpha_{\mathrm{H}} \equiv \alpha-\left(1-\theta_{\mathrm{H}}\right) \delta$ and $\alpha_{\mathrm{L}}$ $\equiv \alpha-\left(1-\theta_{\mathrm{L}}\right) \delta$. However, these consumers do not update their beliefs about safety based on the price charged following non-disclosure. Instead, they naively believe that the product is of high safety and purchase according to the demand curve $\mathrm{q}^{\mathrm{n}}(\mathrm{p}) \equiv\left[\alpha-\left(1-\theta_{\mathrm{H}}\right) \delta-\mathrm{p}\right] / \beta$. The remaining fraction of consumers continue to exercise skeptical beliefs and purchase according to the demand function $\mathrm{q}(\mathrm{p})$ $=[\alpha-(1-\mathrm{B}(\mathrm{p})) \delta-\mathrm{p}] / \beta$.

The firm, accounting for these different consumer populations, faces the demand curve $\hat{\mathrm{q}}(\mathrm{p})$ $\equiv \varepsilon q^{n}(p)+(1-\varepsilon) q(p)=\left[\alpha-\varepsilon\left(1-\theta_{H}\right) \delta-(1-\varepsilon)(1-B(p)) \delta-p\right] / \beta$. This demand curve is similar to the original one except that the expression $\alpha-(1-\mathrm{B}(\mathrm{p})) \delta$ is replaced by $\alpha-\varepsilon\left(1-\theta_{\mathrm{H}}\right) \delta-(1-\varepsilon)(1-$ $\mathrm{B}(\mathrm{p})) \delta$. These two expressions are the same when skeptical consumers infer that the product is of high safety; that is, $\alpha_{\mathrm{H}}=\alpha-\varepsilon\left(1-\theta_{\mathrm{H}}\right) \delta-(1-\varepsilon)\left(1-\theta_{\mathrm{H}}\right) \delta=\alpha-\left(1-\theta_{\mathrm{H}}\right) \delta$. However, when skeptical consumers infer that the product is of low safety, naively optimistic consumers continue to believe it is of high safety. Then there is a modified version of $\alpha_{L}$, denoted $\hat{\alpha}_{L}$, where $\hat{\alpha}_{L} \equiv \alpha-\varepsilon\left(1-\theta_{H}\right) \delta-$ $(1-\varepsilon)\left(1-\theta_{\mathrm{L}}\right) \delta>\alpha_{\mathrm{L}}$

We continue to maintain Assumptions 1 and 2 (substituting $\hat{\alpha}_{\mathrm{L}}$ for $\alpha_{\mathrm{L}}$ ), which means that all of the previous analysis continues to apply with the appropriate substitution of $\hat{\alpha}_{\mathrm{L}}$ for $\alpha_{\mathrm{L}}$. Thus, the separating equilibrium prices and output for the low-safety firm now become : $\hat{\mathrm{P}}_{\mathrm{L}}^{\mathrm{s}}=\left(\hat{\alpha}_{\mathrm{L}}+\mathrm{c}_{\mathrm{L}}\right) / 2$ and $\hat{\Pi}_{L}^{s}=\left(\hat{\alpha}_{L}-c_{L}\right)^{2} / 4 \beta$. Notice that the low-safety firm no longer obtains its true full-information profits (as it would do under disclosure); rather, it obtains the profits it would obtain if skeptical consumers knew it was of low safety, while naive consumers continue to believe that it is of high safety. The separating equilibrium price for the high-safety firm are likewise obtained by substituting $\hat{\alpha}_{\mathrm{L}}$ for $\alpha_{\mathrm{L}}$. This yields the following modified version of Proposition 1. 
Proposition 3. There is a unique (refined) separating perfect Bayesian equilibrium in prices:

(i) the low-safety firm charges $\hat{P}_{\mathrm{L}}^{\mathrm{s}}=\left(\hat{\alpha}_{\mathrm{L}}+\mathrm{c}_{\mathrm{L}}\right) / 2$;

(ii) when $\mathrm{c}_{\mathrm{H}}>\mathrm{c}_{\mathrm{L}}$, then $\hat{\mathrm{P}}_{\mathrm{H}}^{\mathrm{s}}=.5\left(\alpha_{\mathrm{H}}+\mathrm{c}_{\mathrm{L}}+\left\{\left(\alpha_{\mathrm{H}}-\mathrm{c}_{\mathrm{L}}\right)^{2}-\left(\hat{\alpha}_{\mathrm{L}}-\mathrm{c}_{\mathrm{L}}\right)^{2}\right\}^{1 / 2}\right)>\mathrm{P}_{\mathrm{H}}^{\mathrm{f}}$; the beliefs supporting this equilibrium are $\mathrm{B}(\mathrm{p})=\theta_{\mathrm{L}}$ when $\mathrm{p}<\hat{\mathrm{P}}_{\mathrm{H}}^{\mathrm{s}}$ and $\mathrm{B}(\mathrm{p})=\theta_{\mathrm{H}}$ when $\mathrm{p} \geq \hat{\mathrm{P}}_{\mathrm{H}}^{\mathrm{s}}$; (iii) when $c_{L}>c_{H}$, then $\hat{P}_{H}^{s}=\min \left\{.5\left(\alpha_{H}+c_{L}-\left\{\left(\alpha_{H}-c_{L}\right)^{2}-\left(\hat{\alpha}_{L}-c_{L}\right)^{2}\right\}^{1 / 2}\right), P_{H}^{f}\right\} \leq P_{H}^{f}$; the supporting beliefs are $\mathrm{B}(\mathrm{p})=\theta_{\mathrm{L}}$ when $\mathrm{p}>\hat{\mathrm{P}}_{\mathrm{H}}^{\mathrm{s}}$ and $\mathrm{B}(\mathrm{p})=\theta_{\mathrm{H}}$ when $\mathrm{p} \leq \hat{\mathrm{P}}_{\mathrm{H}}^{\mathrm{s}}$.

First we consider the impact of a small fraction of naive consumers on the separating equilibrium when $c_{H}>c_{L}$. Since both $\hat{P}_{L}^{s}$ and $\hat{\Pi}_{L}^{s}$ are increasing functions of $\hat{\alpha}_{L}$, it follows that the addition of naive consumers raises both the equilibrium price and profits for the low-safety firm; that is, $\hat{\mathrm{P}}_{\mathrm{L}}^{\mathrm{s}}>\mathrm{P}_{\mathrm{L}}^{\mathrm{s}}$ and $\hat{\Pi}_{\mathrm{L}}^{s}>\Pi_{\mathrm{L}}^{\mathrm{s}}$. Thus a firm producing a low-safety product benefits from the existence of naive consumers who persistently believe that its product is of higher safety than it really is. What may be less expected is that a firm producing a high-safety product also benefits from the existence of such naive consumers; that is, $\hat{\Pi}_{\mathrm{H}}^{\mathrm{s}}>\Pi_{\mathrm{H}}^{\mathrm{s}}$. To see this, first note that both consumer types are using the correct safety assessment, and hence both purchase according to the demand function $q(p) \equiv[\alpha-$ $\left.\left(1-\theta_{\mathrm{H}}\right) \delta-\mathrm{p}\right] / \beta$; the full-information price $\mathrm{P}_{\mathrm{H}}^{\mathrm{f}}$ maximizes profits given this demand function. Second, recall that the safer firm distorts its price upward (from its full-information price) to signal safety when $c_{H}>c_{L}$. While there is still some upward distortion, since $\hat{P}_{H}^{s}$ is a decreasing function of $\hat{\alpha}_{L}$, it follows that $\hat{\mathrm{P}}_{\mathrm{H}}^{\mathrm{s}}<\mathrm{P}_{\mathrm{H}}^{\mathrm{s}}$. That is, there is less upward distortion, and hence the high-safety firm's price provides higher profits (i.e., $\hat{\Pi}_{\mathrm{H}}^{s}>\Pi_{\mathrm{H}}^{\mathrm{s}}$ ) when there are some naive consumers,

The intuition for this result is as follows. Naive consumers buy from a low-safety firm as if it were a high-safety firm, which increases the low-safety firm's profits in a separating equilibrium. Consequently, there is a reduced temptation for the low-safety firm to mimic the high- 
safety firm's price (its sales volume would still go up if it were inferred to be of high safety, but now only among skeptical consumers). Since the high-safety firm's price is set so as to just deter mimicry by the low-safety firm, the high-safety firm can lower its price toward its full-information optimum, which improves its profits.

In addition to this externality between the two types of firm, there is an externality between the two types of consumer. In particular, the naive consumers raise the price in state L (since they purchase as if the product were of high safety, driving up the price) and lower the price in state $\mathrm{H}$ (since the high-safety firm need not distort its price upward as much to signal high safety).

Next we consider the impact of a small fraction of naive consumers on the separating equilibrium when $\mathrm{c}_{\mathrm{L}}>\mathrm{c}_{\mathrm{H}}$. The impact of naive consumers on the low-safety firm is the same: both prices and profits are higher. Moreover, the high-safety firm continues to benefit from the presence of naive consumers, though the effect on its price is reversed. Both consumer types are using the correct safety assessment, and hence both purchase according to the demand function $q(p) \equiv[\alpha-(1-$ $\left.\left.\theta_{\mathrm{H}}\right) \delta-\mathrm{p}\right] / \beta$, but the safer firm distorts its price downward from its full-information price to signal safety when $\mathrm{c}_{\mathrm{L}}>\mathrm{c}_{\mathrm{H}} \cdot{ }^{25}$ While there is still some downward distortion, since $\hat{\mathrm{P}}_{\mathrm{H}}^{\mathrm{s}}$ is now an increasing function of $\hat{\alpha}_{\mathrm{L}}$, it follows that $\hat{\mathrm{P}}_{\mathrm{H}}^{\mathrm{s}}>\mathrm{P}_{\mathrm{H}}^{\mathrm{s}}$. That is, there is less downward distortion, and hence the high-safety firm's price provides higher profits (since it is closer to the full-information optimum) when there are some naive consumers. The intuition for why the high-safety firm benefits is also precisely the same as when $c_{H}>c_{L}$. The low-safety firm's higher equilibrium profits imply a reduced temptation for the low-safety firm to mimic the high-safety firm. Since the high-safety

${ }^{25}$ Distortion occurs when the high-safety firm's cost disadvantage is moderate; when it is large, then naive consumers have no effect on the high-safety firm's price or profits in a separating equilibrium. 
firm's price is set so as to just deter mimicry by the low-safety firm, the high-safety firm can raise its price toward its full-information optimum, which improves its profits. Naive consumers now cause higher prices in both states of the world.

Finally, the effect of naive consumers on incentives for disclosure are adverse regardless of the ordering of costs. A firm producing a low-safety product would not disclose even if the cost of disclosure were zero (it prefers to milk the naive consumers), since $\hat{\Pi}_{\mathrm{L}}^{\mathrm{s}}>\Pi_{\mathrm{L}}^{\mathrm{s}}=\Pi_{\mathrm{L}}^{\mathrm{f}}$. The high-safety firm's incentive to disclose is also reduced; since $\hat{\Pi}_{\mathrm{H}}^{\mathrm{s}}>\Pi_{\mathrm{H}}^{\mathrm{s}}$, it follows that $\Pi_{\mathrm{H}}^{\mathrm{f}}-\hat{\Pi}_{\mathrm{H}}^{\mathrm{s}}<\Pi_{\mathrm{H}}^{\mathrm{f}}-\Pi_{\mathrm{H}}^{\mathrm{s}}$. Thus, one might ask whether a firm's response to consumer naivete might be to engage in more disclosure. We find that if "naivete" is interpreted as a persistent belief in high quality, then the answer is "No." Neither type of firm benefits from disabusing consumers of this form of naivete.

\section{Summary and Conclusions}

In this paper, we have considered two channels through which consumers might learn about product safety and how liability influences the use of these channels. First, a firm with private information about the safety of its good might make a credible (but costly) voluntary disclosure. If the firm does not make a voluntary disclosure, then consumers will attempt to infer safety from the product's price. We find that when the firm does not face substantial liability for a consumer's harm (which corresponds to marginal cost increasing in safety), then higher safety is signaled by a price which is distorted upward from its full-information value. Since disclosure allows the safer firm to lower its price and sell more output, it is the safer firm that will elect to disclose its safety voluntarily if the disclosure cost is not prohibitive. However, it will do so less often than would be socially optimal, since it considers only the gain in profits and not the accompanying gain in 
consumer surplus that arises from the lower price and higher output. On the other hand, when the firm does face substantial liability for a consumer's harm (which corresponds to marginal cost decreasing in safety), then higher safety is signaled by a price which is distorted downward from its full-information value. In this case, disclosure would allow the safer firm to raise its price and sell less output, which improves its profits but reduces consumer (and total) surplus. Again, it is the safer firm that will elect to disclose its safety if the disclosure cost is not prohibitive, but now all disclosure is welfare-impairing.

We considered the possibility that some fraction of consumers may be naively optimistic (rather than skeptical), and always purchase as if the product were of high safety. This turns out to improve the profits of both low-safety and high-safety firm types. A low-safety firm is better off because naively-optimisitc consumers demand more at the same price than do skeptical consumers (who recognize that the firm's product is of low safety). A high-safety firm is better off because the improvement in low-safety profits reduces the low-safety firm's incentive to mimic the price of the high-safety firm, which allows the high-safety firm to distort its price less (either upward or downward, as dictated by the cost configuration) from its full-information price. Thus, the firm's response to naively-optimistic consumers is not to engage in greater disclosure; the low-safety firm type still has no incentive to disclosure while the high-safety firm type's incentive to disclose is reduced.

Mandatory disclosure could be beneficial in some circumstances, though they are quite limited. In part, this is because this model recognizes that information will be transmitted through the price, if not through direct disclosure. Moreover, the way the information is transmitted through signaling may be socially beneficial, as occurs when the firm distorts its price downward from its 
full-information monopoly price. Of course, this latter result requires that the firm face substantial liability for a consumer's loss; specifically, $\gamma>\mathrm{k}$. Of course, this is affected if there are imperfections in enforcement,, making the firm's loss less than $\gamma$ and shifting the differential to the consumer. Examples readily come to mind: 1) failure to file; 2) problems of proving causation; and 3) difficulties in proving duty or fault; 4) and caps on damage awards. Such difficulties can shift the result to being somewhat more supportive of the circumstances that make mandatory disclosure socially desirable. 
Appendix for "Products Liability, Signaling and Disclosure"

Derivation of a unique (refined) separating signaling equilibrium when the disclosure cost is prohibitively high

When the disclosure cost is prohibitively high, then neither firm will engage in disclosure; any information transmission will occur through signaling. As shown in the text, the payoff function for a firm charging a price $p$, whose true safety is $\theta_{i}$ and whose perceived safety is $\widetilde{\theta}$, is given by $\pi(p$, $\left.\theta_{\mathrm{i}}, \widetilde{\theta}\right)=\left(\mathrm{p}-\mathrm{c}_{\mathrm{i}}\right)(\alpha-(1-\widetilde{\theta}) \delta-\mathrm{p}) / \beta$.

When neither firm type discloses its safety, consumers will look to the price for information about safety. We first note that no firm type would distort its price away from its full-information price in order to be taken as an L-type firm. Hence, in a separating equilibrium, the L-type firm will charge $\mathrm{P}_{\mathrm{L}}^{\mathrm{s}}=\mathrm{P}_{\mathrm{L}}^{\mathrm{f}}=\left(\alpha_{\mathrm{L}}+\mathrm{c}_{\mathrm{L}}\right) / 2$ and receive its full-information profits $\Pi_{\mathrm{L}}^{\mathrm{s}}=\Pi_{\mathrm{L}}^{\mathrm{f}}=\left(\alpha_{\mathrm{L}}-\mathrm{c}_{\mathrm{L}}\right)^{2} / 4 \beta$. However, the H-type firm is willing to distort its price (at least to some extent) in order to be taken as an $\mathrm{H}$-type firm. If an H-type firm is to use its price to signal high safety, it must charge a price $\mathrm{P}_{\mathrm{H}}^{\mathrm{s}}$ such that:

(1) the $\mathrm{H}$-type firm prefers to charge $\mathrm{P}_{\mathrm{H}}^{\mathrm{s}}$ and be taken as an $\mathrm{H}$-type firm rather than to charge any other price (and perhaps to be taken as an L-type firm); and

(2) the L-type firm would not find it profitable to mimic this price, even if by doing so it would be taken as an H-type firm.

First, consider condition (1). If the H-type firm allows itself to be taken as an L-type firm, its best price is the one that maximizes $\pi\left(p, \theta_{\mathrm{H}}, \theta_{\mathrm{L}}\right)$. That is, the firm will charge $\rho_{\mathrm{HL}} \equiv\left(\alpha_{\mathrm{L}}+\mathrm{c}_{\mathrm{H}}\right) / 2$ and receive profits of $\Pi_{\mathrm{HL}} \equiv\left(\alpha_{\mathrm{L}}-\mathrm{c}_{\mathrm{H}}\right)^{2} / 4 \beta$. Thus, the incentive compatibility condition (ICH) implies:

$$
\left(\mathrm{P}_{\mathrm{H}}^{\mathrm{s}}-\mathrm{c}_{\mathrm{H}}\right)\left(\alpha_{\mathrm{H}}-\mathrm{P}_{\mathrm{H}}^{\mathrm{s}}\right) / \beta \geq\left(\alpha_{\mathrm{L}}-\mathrm{c}_{\mathrm{H}}\right)^{2} / 4 \beta,
$$

which is satisfied for all

$\mathrm{P}_{\mathrm{H}}^{\mathrm{s}} \in \mathrm{A} \equiv\left[\mathrm{a}_{1}, \mathrm{a}_{2}\right]=\left[.5\left(\alpha_{\mathrm{H}}+\mathrm{c}_{\mathrm{H}}-\left\{\left(\alpha_{\mathrm{H}}-\mathrm{c}_{\mathrm{H}}\right)^{2}-\left(\alpha_{\mathrm{L}}-\mathrm{c}_{\mathrm{H}}\right)^{2}\right\}^{1 / 2}\right), .5\left(\alpha_{\mathrm{H}}+\mathrm{c}_{\mathrm{H}}+\left\{\left(\alpha_{\mathrm{H}}-\mathrm{c}_{\mathrm{H}}\right)^{2}-\left(\alpha_{\mathrm{L}}-\mathrm{c}_{\mathrm{H}}\right)^{2}\right\}^{1 / 2}\right)\right]$.

Note that the H-type firm's full information price is given by $\mathrm{P}_{\mathrm{H}}^{\mathrm{f}} \equiv\left(\alpha_{\mathrm{H}}+\mathrm{c}_{\mathrm{H}}\right) / 2$ and that $\mathrm{P}_{\mathrm{H}}^{\mathrm{f}} \in\left[\mathrm{a}_{1}, \mathrm{a}_{2}\right]$.

Next, consider condition (2). If the L-type firm were to charge the price $\mathrm{P}_{\mathrm{H}}^{\mathrm{s}}$ and it was therefore inferred to be of type $H$, it would obtain profits of $\Pi_{L H} \equiv\left(\mathrm{P}_{\mathrm{H}}^{\mathrm{s}}-\mathrm{c}_{\mathrm{L}}\right)\left(\alpha_{\mathrm{H}}-\mathrm{P}_{\mathrm{H}}^{\mathrm{s}}\right) / \beta$. Thus, the incentive compatibility condition (ICL) implies:

$$
\left(\alpha-\left(1-\theta_{\mathrm{L}}\right) \delta-\mathrm{c}_{\mathrm{L}}\right)^{2} / 4 \beta \geq\left(\mathrm{P}_{\mathrm{H}}^{\mathrm{s}}-\mathrm{c}_{\mathrm{L}}\right)\left(\alpha-\left(1-\theta_{\mathrm{H}}\right) \delta-\mathrm{P}_{\mathrm{H}}^{\mathrm{s}}\right) / \beta,
$$

which is satisfied for all 
$\mathrm{P}_{\mathrm{H}}^{\mathrm{s}} \notin \mathrm{B} \equiv\left(\mathrm{b}_{1}, \mathrm{~b}_{2}\right)=\left[.5\left(\alpha_{\mathrm{H}}+\mathrm{c}_{\mathrm{L}}-\left\{\left(\alpha_{\mathrm{H}}-\mathrm{c}_{\mathrm{L}}\right)^{2}-\left(\alpha_{\mathrm{L}}-\mathrm{c}_{\mathrm{L}}\right)^{2}\right\}^{1 / 2}\right), .5\left(\alpha_{\mathrm{H}}+\mathrm{c}_{\mathrm{L}}+\left\{\left(\alpha_{\mathrm{H}}-\mathrm{c}_{\mathrm{L}}\right)^{2}-\left(\alpha_{\mathrm{L}}-\mathrm{c}_{\mathrm{L}}\right)^{2}\right\}^{1 / 2}\right)\right]$.

Thus, any price belonging to the set $\mathrm{A}$ but not the set $\mathrm{B}$ provides a separating equilibrium price for the H-type firm. Each of these equilibria is supported by consumer beliefs that interpret any other price as coming from an L-type firm. The Intuitive Criterion (Cho and Kreps, 1987) argues that such beliefs are unreasonable, since no L-type would choose such a price even if it would be inferred to be an H-type; rather, consumers should infer that such prices are associated with an $\mathrm{H}$-type firm. Under these reasonable beliefs, the H-type firm would select the price that sacrifices the least profit relative to the full-information benchmark.

The following functions and their properties will be used in the proofs of two lemmas. Let $\mathrm{g}(\mathrm{c}) \equiv .5\left(\alpha_{\mathrm{H}}+\mathrm{c}-\left\{\left(\alpha_{\mathrm{H}}-\mathrm{c}\right)^{2}-\left(\alpha_{\mathrm{L}}-\mathrm{c}\right)^{2}\right\}^{1 / 2}\right)$. Since $\alpha_{\mathrm{H}}>\alpha_{\mathrm{L}}>0$, it follows that $\mathrm{g}^{\prime}(\mathrm{c})>0$. Let $\mathrm{h}(\mathrm{c}) \equiv$ $.5\left(\alpha_{\mathrm{H}}+\mathrm{c}+\left\{\left(\alpha_{\mathrm{H}}-\mathrm{c}\right)^{2}-\left(\alpha_{\mathrm{L}}-\mathrm{c}\right)^{2}\right\}^{1 / 2}\right)$. Under the maintained assumption that $\alpha_{\mathrm{L}}>\max \left\{\mathrm{c}_{\mathrm{H}}, \mathrm{c}_{\mathrm{L}}\right\}$ (Assumption 2), it follows that $\mathrm{h}^{\prime}(\mathrm{c})>0$.

Lemma 1. If $c_{H}>c_{L}$, then (i) $b_{1}<a_{1}$ and (ii) $a_{2}>b_{2}>P_{H}^{f}$.

Proof of Lemma 1. Assume that $c_{H}>c_{L}$. (i) Note that $b_{1}=g\left(c_{L}\right)$ and $a_{1}=g\left(c_{H}\right)$. Since $g^{\prime}(c)>0$, it follows that $b_{1}<a_{1}$. (ii) To see that the first inequality holds, note that $b_{2}=h\left(c_{L}\right)$ and $a_{2}=h\left(c_{H}\right)$. Since $h^{\prime}(c)>0$, it follows that $a_{2}>b_{2}$. The second inequality also holds, under the maintained assumptions that $\alpha_{\mathrm{H}}-\mathrm{c}_{\mathrm{H}}>\alpha_{\mathrm{L}}-\mathrm{c}_{\mathrm{L}}$ and $\alpha_{\mathrm{L}}>\max \left\{\mathrm{c}_{\mathrm{H}}, \mathrm{c}_{\mathrm{L}}\right\}$ (Assumptions 1 and 2, resp.). QED

Lemma 1 (along with the fact that $\mathrm{P}_{\mathrm{H}}^{\mathrm{f}} \in\left[\mathrm{a}_{1}, \mathrm{a}_{2}\right]$ ) provides a complete ordering of the five prices, demonstrating that the set of prices in $A$ but not in $B=\left[b_{2}, a_{2}\right]$ when $c_{H}>c_{L}$. The implication of Lemma 1 is that, although a price $\mathrm{P}_{\mathrm{H}}^{\mathrm{s}}<\mathrm{b}_{1}$ would deter mimicry, the H-type would prefer to allow itself to be taken as an L-type rather than use such a $\mathrm{P}_{\mathrm{H}}^{\mathrm{s}}$ to signal its true type $(\mathrm{H})$. On the other hand, there is an interval of prices $\left[b_{2}, a_{2}\right]$, all of which involve pricing above the H-type's full-information price, that both deter mimicry by type $\mathrm{L}$ and are preferable for $\mathrm{H}$ to allowing itself to be taken for an L-type. Thus, when $\mathrm{c}_{\mathrm{H}}>\mathrm{c}_{\mathrm{L}}$, the H-type will signal high safety by distorting its price upward (relative to full information). The price that conveys this signal with the least distortion (and thus sacrifices the least profit) is $\mathrm{P}_{\mathrm{H}}^{\mathrm{s}}=\mathrm{b}_{2}$.

Lemma 2. If $\mathrm{c}_{\mathrm{L}}>\mathrm{c}_{\mathrm{H}}$, then (i) $\mathrm{b}_{2}>\mathrm{a}_{2}$; (ii) $\mathrm{a}_{1}<\mathrm{b}_{1}$; and (iii) $\mathrm{b}_{1}(<=>) \mathrm{P}_{\mathrm{H}}^{\mathrm{f}}$ as $\left(\mathrm{c}_{\mathrm{L}}-\mathrm{c}_{\mathrm{H}}\right)^{2}(<=>)\left(\alpha_{\mathrm{H}}-\right.$ $\left.\alpha_{L}\right)\left(\alpha_{H}+\alpha_{L}-2 c_{L}\right)$.

Proof of Lemma 2. Assume that $c_{L}>c_{H}$. (i) Note that $b_{2}=h\left(c_{L}\right), a_{2}=h\left(c_{H}\right)$, and recall that $h^{\prime}(c)>$ 0 . Since $c_{L}>c_{H}$, it follows that $b_{2}>a_{2}$. (ii) Note that $b_{1}=g\left(c_{L}\right), a_{1}=g\left(c_{H}\right)$, and recall that $g^{\prime}(c)>$ 0 . Since $c_{L}>c_{H}$, it follows that $b_{1}>a_{1}$. (iii) This follows directly from comparing the two expressions. QED

Lemma 2 (along with the fact that $\mathrm{P}_{\mathrm{H}}^{\mathrm{f}} \in\left[\mathrm{a}_{1}, \mathrm{a}_{2}\right]$ ) provides a complete ordering of the five prices, demonstrating that the set of prices in $A$ but not in $\mathrm{B}=\left[\mathrm{a}_{1}, \mathrm{~b}_{1}\right]$ when $\mathrm{c}_{\mathrm{H}}>\mathrm{c}_{\mathrm{L}}$. The implication of Lemma 1 is that, although a price $\mathrm{P}_{\mathrm{H}}^{\mathrm{s}}>\mathrm{b}_{2}$ would deter mimicry, the H-type would prefer to allow itself to be taken as an L-type rather than use such a $\mathrm{P}_{\mathrm{H}}^{\mathrm{s}}$ to signal its true type $(\mathrm{H})$. On the other hand, 
there is an interval of prices $\left[a_{1}, b_{1}\right]$, that both deter mimicry by type $\mathrm{L}$ and are preferable for $\mathrm{H}$ to allowing itself to be taken for an L-type.

As can be seen from part (iii), when $\mathrm{c}_{\mathrm{L}}-\mathrm{c}_{\mathrm{H}}$ is "moderate," then $\mathrm{b}_{1}<\mathrm{P}_{\mathrm{H}}^{\mathrm{f}}$ and hence $\mathrm{P}_{\mathrm{H}}^{\mathrm{f}}$ cannot be used to signal high safety; the H-type firm must signal high safety by distorting its price downward (relative to full information). To get an idea of what it means for $c_{L}-c_{H}$ to be "moderate," note that if the H-type firm's full-information price is higher than that of the L-type firm - that is, if $\mathrm{P}_{\mathrm{H}}^{\mathrm{f}}=\left(\alpha_{\mathrm{H}}+\mathrm{c}_{\mathrm{H}}\right) / 2>\left(\alpha_{\mathrm{L}}+\mathrm{c}_{\mathrm{L}}\right) / 2=\mathrm{P}_{\mathrm{L}}^{\mathrm{f}}-$ then $\mathrm{c}_{\mathrm{L}}-\mathrm{c}_{\mathrm{H}}<\alpha_{\mathrm{H}}-\alpha_{\mathrm{L}}$ and $\mathrm{c}_{\mathrm{L}}-\mathrm{c}_{\mathrm{H}}<\alpha_{\mathrm{H}}+\alpha_{\mathrm{L}}-2 \mathrm{c}_{\mathrm{L}}$, which ensures that $b_{1}<\mathrm{P}_{\mathrm{H}}^{\mathrm{f}}$. In order to have $\mathrm{b}_{1}>\mathrm{P}_{\mathrm{H}}^{\mathrm{f}}$, so that the H-type firm can signal with its fullinformation price, $\mathrm{c}_{\mathrm{L}}$ must be "large" relative to $\mathrm{c}_{\mathrm{H}}$. Again, the Intuitive Criterion selects from the interval $\left[a_{1}, b_{1}\right]$ the price that sacrifices the least profit (relative to full information), and hence $\mathrm{P}_{\mathrm{H}}^{\mathrm{s}}$ $=\min \left\{b_{1}, P_{H}^{f}\right\}$.

Finally, it is straightforward to verify that $\mathrm{P}_{\mathrm{H}}^{\mathrm{s}} \in\left(\mathrm{c}_{\mathrm{H}}, \alpha_{\mathrm{H}}\right)$ under the maintained assumptions that $\alpha_{\mathrm{H}}-\alpha_{\mathrm{L}}>\mathrm{c}_{\mathrm{H}}-\mathrm{c}_{\mathrm{L}}$ and $\alpha_{\mathrm{L}}>\max \left\{\mathrm{c}_{\mathrm{H}}, \mathrm{c}_{\mathrm{L}}\right\}$ (Assumptions1 and 2, resp.); thus, both the equilibrium price-cost margin and output are positive for the H-type firm. Since the L-type firm uses its fullinformation price, its equilibrium price-cost margin and output are also positive.

\section{Characterization of pooling equilibria and elimination via refinement}

In this section we first characterize a pooling equilibrium, in which both firms charge the same price, denoted $\mathrm{P}^{\mathrm{P}}$. We then argue that no such equilibrium survives refinement using the Intuitive Criterion.

If both firms charge the same price $\mathrm{P}^{\mathrm{P}}$, then consumers believe that the firm is of type $\mathrm{H}$ with probability $\lambda$, in which case they demand $\left(\alpha_{H}-P^{P}\right) / \beta$ units, and of type $L$ with probability $1-\lambda$, in which case they demand $\left(\alpha_{\mathrm{L}}-\mathrm{P}^{\mathrm{P}}\right) / \beta$ units. Let $\bar{\alpha} \equiv \lambda \alpha_{\mathrm{H}}+(1-\lambda) \alpha_{\mathrm{L}}$. Then both firms expect to sell $\left(\bar{\alpha}-\mathrm{P}^{\mathrm{P}}\right) / \beta$ units if they charge the price $\mathrm{P}^{\mathrm{P}}$. Both firms will pool at a price $\mathrm{P}^{\mathrm{P}}$ if the following incentive compatibility constraints hold:

i) $\left(\mathrm{P}^{\mathrm{P}}-\mathrm{c}_{\mathrm{H}}\right)\left(\bar{\alpha}-\mathrm{P}^{\mathrm{P}}\right) / \beta \geq \max _{\mathrm{p}}\left(\mathrm{p}-\mathrm{c}_{\mathrm{H}}\right)\left(\alpha_{\mathrm{L}}-\mathrm{p}\right) / \beta$ and ii) $\left(\mathrm{P}^{\mathrm{P}}-\mathrm{c}_{\mathrm{L}}\right)\left(\bar{\alpha}-\mathrm{P}^{\mathrm{P}}\right) / \beta \geq \max _{\mathrm{p}}\left(\mathrm{p}-\mathrm{c}_{\mathrm{L}}\right)\left(\alpha_{\mathrm{L}}-\mathrm{p}\right) / \beta$.

These inequalities indicate that both types would prefer to charge the pooling price and sell the average quantity demanded at that price, rather than deviating to any other price and being taken as an L-type firm. That is, the pooling price is supported by beliefs that assign the worst type (type L) to any price other than the pooling price. Any price $\mathrm{P}^{\mathrm{P}}$ satisfying these two inequalities provides a pooling equilibrium.

We need not actually construct a pooling equilibrium, as we need only show that if one exists, then there is a price to which the H-type firm could profitably defect and that would be unprofitable for an L-type firm, even if the consumer were to update her beliefs and infer that the signal came from an $\mathrm{H}$-type firm. Thus, $\mathrm{P}^{\mathrm{P}}$ fails the Intuitive Criterion if there exists $\mathrm{P}^{*}$ such that:

(iii) $\left(\mathrm{P}^{*}-\mathrm{c}_{\mathrm{H}}\right)\left(\alpha_{\mathrm{H}}-\mathrm{P}^{*}\right) / \beta \geq\left(\mathrm{P}^{\mathrm{P}}-\mathrm{c}_{\mathrm{H}}\right)\left(\bar{\alpha}-\mathrm{P}^{\mathrm{P}}\right) / \beta$ and iv) $\left(\mathrm{P}^{*}-\mathrm{c}_{\mathrm{L}}\right)\left(\alpha_{\mathrm{H}}-\mathrm{P}^{*}\right) / \beta \leq\left(\mathrm{P}^{\mathrm{P}}-\mathrm{c}_{\mathrm{L}}\right)\left(\bar{\alpha}-\mathrm{P}^{\mathrm{P}}\right) / \beta$. 
In the inequalities (iii)-(iv), the left-hand-side of each inequality is the profit that would be obtained by (respectively) the H-type and L-type firms by defecting (and being taken to be an H-type firm after the consumer has updated her beliefs), while the profits from the pooling equilibrium appear on the right-hand-side.

Let us denote the roots to the equality version of inequality (iii) as $\mathrm{P}_{\mathrm{H}}^{-}$and $\mathrm{P}_{\mathrm{H}}^{+}>\mathrm{P}_{\mathrm{H}}^{-}$, and the roots to the equality version of inequality (iv) as $\mathrm{P}_{\mathrm{L}}^{-}$and $\mathrm{P}_{\mathrm{L}}^{+}>\mathrm{P}_{\mathrm{L}}^{-}$. Then satisfaction of the inequalities (iii)-(iv) is equivalent to asking if there exists $\mathrm{P}^{*}$ such that $\mathrm{P}^{*} \in\left[\mathrm{P}_{\mathrm{H}}^{-}, \mathrm{P}_{\mathrm{H}}^{+}\right]$and $\mathrm{P}^{*} \notin$ $\left[\mathrm{P}_{\mathrm{L}}^{-}, \mathrm{P}_{\mathrm{L}}^{+}\right]$; if so, then $\mathrm{P}^{\mathrm{P}}$ fails the Intuitive Criterion.

The roots for the equality versions of inequalities (iii)-(iv) are given by:

and

$$
\mathrm{P}_{\mathrm{i}}^{+}=.5\left(\alpha_{\mathrm{H}}+\mathrm{c}_{\mathrm{i}}+\left\{\left(\alpha_{\mathrm{H}}-\mathrm{c}_{\mathrm{i}}\right)^{2}-4\left(\mathrm{P}^{\mathrm{P}}-\mathrm{c}_{\mathrm{i}}\right)\left(\bar{\alpha}-\mathrm{P}^{\mathrm{P}}\right)\right\}^{1 / 2}\right)
$$

$$
\mathrm{P}_{\mathrm{i}}^{-}=.5\left(\alpha_{\mathrm{H}}+\mathrm{c}_{\mathrm{i}}-\left\{\left(\alpha_{\mathrm{H}}-\mathrm{c}_{\mathrm{i}}\right)^{2}-4\left(\mathrm{P}^{\mathrm{P}}-\mathrm{c}_{\mathrm{i}}\right)\left(\bar{\alpha}-\mathrm{P}^{\mathrm{P}}\right)\right\}^{1 / 2}\right), \text { for } \mathrm{i}=\mathrm{H}, \mathrm{L} \text {. }
$$

It is straightforward to show that $\mathrm{P}_{\mathrm{H}}^{+}(>=<) \mathrm{P}_{\mathrm{L}}^{+}$and $\mathrm{P}_{\mathrm{H}}^{-}(>=<) \mathrm{P}_{\mathrm{L}}^{-}$as $\mathrm{c}_{\mathrm{H}}(>=<) \mathrm{c}_{\mathrm{L}}$. Thus, if $\mathrm{c}_{\mathrm{H}}>\mathrm{c}_{\mathrm{L}}$, then there is a non-empty interval of prices $\left[\mathrm{P}_{\mathrm{L}}^{+}, \mathrm{P}_{\mathrm{H}}^{+}\right]$satisfying (iii)-(iv), and any $\mathrm{P}^{*}$ in this interval upsets the pooling equilibrium. On the other hand, if $\mathrm{c}_{\mathrm{L}}>\mathrm{c}_{\mathrm{H}}$, then there is a non-empty interval of prices $\left[\mathrm{P}_{\mathrm{H}}^{-}, \mathrm{P}_{\mathrm{L}}^{-}\right]$satisfying (iii)-(iv), and any $\mathrm{P}^{*}$ in this interval upsets the pooling equilibrium (recall that we explicitly eliminate the knife-edge case of $\mathrm{c}_{\mathrm{H}}>\mathrm{cL}$, or, equivalently, $\mathrm{k}$ $=\gamma$; see footnote 13). Thus no pooling equilibrium survives refinement. 


\section{References}

Arlen, Jennifer and William Bunting. "Signaling Quality Through Renegotiable Contractual Liability,” Working Paper, New York University Law School, April 2006.

Bagwell, Kyle. "Pricing to Signal Product Line Quality," Journal of Economics and Management Strategy 1 (1992), 151-174.

Bagwell, Kyle and Michael Riordan. "High and Declining Prices Signal Product Quality," American Economic Review 81 (1991), 224-239.

Bester, Helmut. "Quality Uncertainty Mitigates Product Differentiation," RAND Journal of Economics 29 (1998), 828-844.

Board, Oliver. "Competition and Disclosure," Working Paper, Department of Economics, University of Pittsburgh, November 2003.

Cai, Hongbin, John Riley, and Lixin Ye. "Reserve Price Signaling,” Journal of Economic Theory, forthcoming.

Caldieraro, Fabio, Dongsoo Shin, and Andrew E. Stivers. "Voluntary Quality Disclosure Under Price-Signaling Competition," Working Paper, Department of Economics, Santa Clara University, January 2007.

Cheong, Insuk and Jeong-Yoo Kim. "Costly Information Disclosure in Oligopoly,” Journal of Industrial Economics 52 (2004), 121-132.

Cho, In-Koo and David M. Kreps. "Signaling Games and Stable Equilibria," Quarterly Journal of Economics 102 (1987), 179-221.

Daughety, Andrew F. and Jennifer F. Reinganum. "Product Safety: Liability, R\&D and Signaling," American Economic Review 85 (1995), 1187-1206. 
Daughety, Andrew F. and Jennifer F. Reinganum. "Secrecy and Safety," American Economic Review 95 (2005), 1074-91.

Daughety, Andrew F. and Jennifer F. Reinganum. "Communicating Quality: A Unified Model of Disclosure and Signaling,” working paper, Vanderbilt University, December 2006.

Daughety, Andrew F. and Jennifer F. Reinganum. "Imperfect Competition and Quality Signaling," Working Paper No. 05-W20, Department of Economics, Vanderbilt University, June 2005; last revised February 2006.

Daughety, Andrew F. and Jennifer F. Reinganum. "Competition and Confidentiality: Signaling Quality in a Duopoly When There is Universal Private Information," forthcoming, Games and Economic Behavior, 2007.

Fluet, Claude and Paolo G. Garella. "Advertising and Prices as Signals of Quality in a Regime of Price Rivalry,” International Journal of Industrial Organization 20 (2002), 907-930.

Grossman, Sanford. "The Informational Role of Warranties and Private Disclosure about Product Quality,” Journal of Law and Economics 24 (1981), 461-483.

Hagerty, Kathleen M. and Michael J. Fishman. "Mandatory versus Voluntary Disclosure in Markets with Informed and Uninformed Customers," Journal of Law, Economics, and Organization 19 (2003), 45-63.

Hertzendorf, Mark N. and Per Baltzer Overgaard. "Prices as Signals of Quality in Duopoly," Working Paper (2001a).

Hertzendorf, Mark N. and Per Baltzer Overgaard. "Price Competition and Advertising Signals: Signaling by Competing Senders," Journal of Economics and Management Strategy 10 (2001b), 621-662. 
Hotz, V. Joseph and Mo Xiao. "Strategic Information Disclosure: The Case of Multi-Attribute Products with Heterogeneous Consumers,” Working Paper, August 2005.

Jovanovic, Boyan. “Truthful Disclosure of Information,” Bell Journal of Economics 13 (1982), 3644.

Klein, Benjamin, and Keith B. Leffler. "The Role of Market Forces in Assuring Contractual Performance," Journal of Political Economy 89 (1981), 615-641.

Levin, Dan, James Peck and Lixin Ye. "Quality Disclosure and Competition,” Working Paper, Department of Economics, Ohio State University, January 2005.

Matthews, Steven A. and Andrew Postlewaite. “Quality Testing and Disclosure,” RAND Journal of Economics 16 (1985), 328-340.

Milgrom, Paul. “Good News and Bad News: Representation Theorems and Applications,” Bell Journal of Economics 12 (1981), 380-391.

Milgrom, Paul and John Roberts. "Price and Advertising Signals of Product Quality,” Journal of Political Economy 94 (1986a), 796-821.

Milgrom, Paul and John Roberts. "Relying on the Information of Interested Parties,” $\underline{\text { RAND Journal }}$ of Economics 17 (1986b), 18-32.

Polinsky, A. Mitchell and Steven Shavell. "Mandatory versus Voluntary Disclosure of Product Risks,” Working Paper, July 2006.

Rea, Samuel A., Jr. "Penalty Doctrine in Contract Law," in The New Palgrave Dictionary of Economics and the Law, Vol. 3, pp. 23-27, edited by Peter Newman, New York: Stockton Press, 1998.

Shavell, Steven. "Acquisition and Disclosure of Information Prior to Sale," 
Economics 25 (1994), 20-36.

Shieh, Shiou. "Incentives for Cost-Reducing Investment in a Signalling Model of Product Quality," RAND Journal of Economics 24 (1993), 466-477.

Viscusi, W. Kip. “A Note on 'Lemons' Markets with Quality Certification,” Bell Journal of Economics 9 (1978), 277-279. 